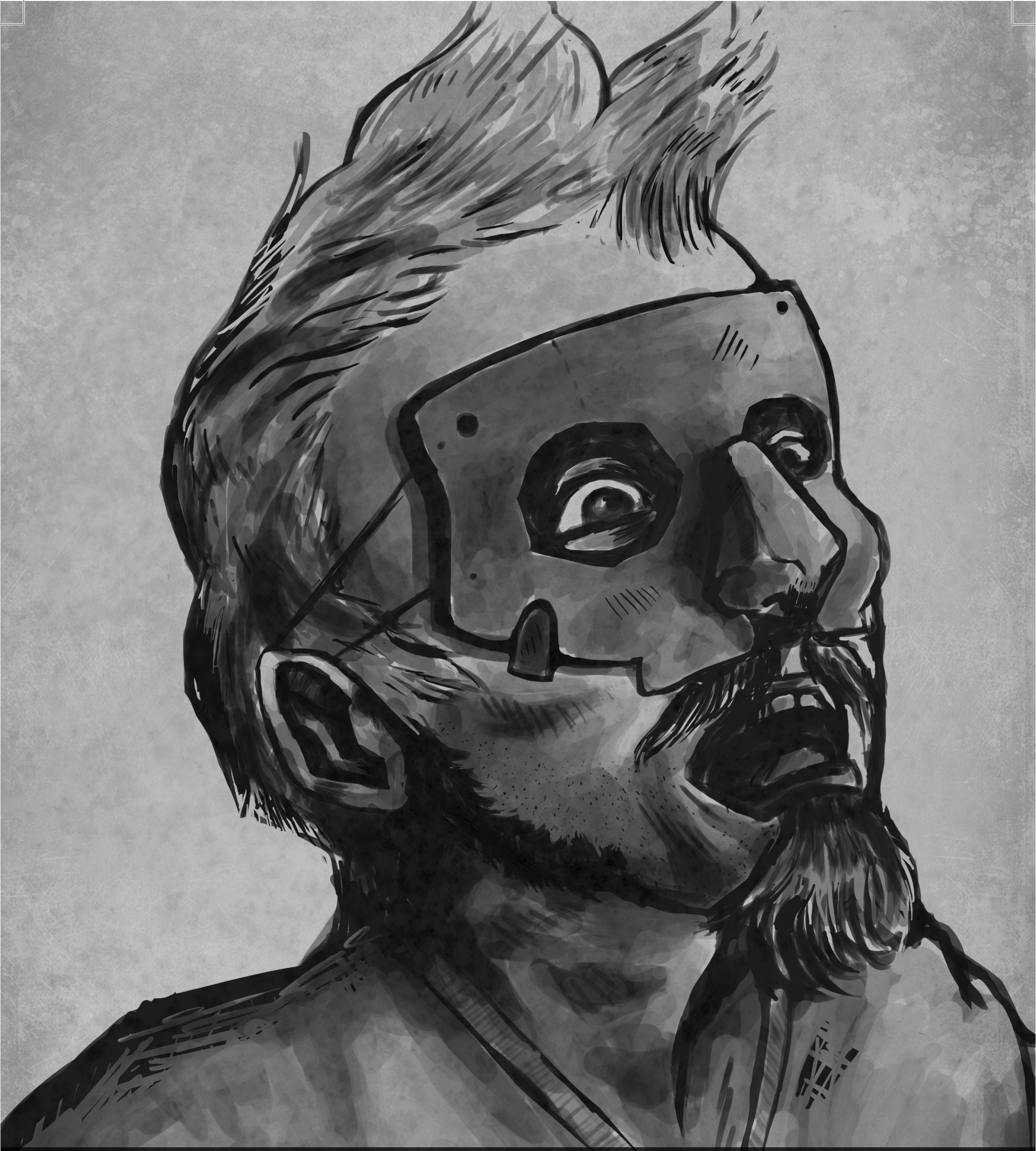

Reivindicación política, resistencia y desarrollo social en organizaciones de recicladores de Bogotá 


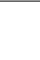




\section{Reivindicación política, resistencia y desarrollo social en organizaciones de recicladores de Bogotá}

Fecha de recepción: 31 de agosto de 2011

Fecha de aprobación: 26 de septiembre de 2011

\author{
Ps. Mg Germán Andrés Cortés Millán \\ (Grupo GOCE)
}

Universidad Piloto de Colombia

Maestría en Planeación Socioeconómica

Especialista en Eucación e Investigador y

consultor en Desarrollo Social.

\section{Resumen}

El siguiente artículo es producto de la investigación realizada por el grupo GOCE (Gestión y organizaciones desde corrientes emergentes), denominada caracterización organizacional y psicosocial de la población de recicladores de la localidad de Chapinero. El artículo recoge, desde una mirada crítica, la contextualización acerca del modelo económico instalado en las prácticas de las organizaciones latinoamericanas, las cuales se reproducen en procesos sociales y afectan de manera directa población como la de los recicladores. Por esta razón, se hace un acercamiento a las formas de organización que tienen los recicladores, resca- tándose la forma como se emprenden procesos de empoderamiento como apuesta para la acción política y para la reivindicación de derechos fundamentales en la población, en el marco de una propuesta de sustentabilidad y autogestión.

\section{Palabras clave}

Organización, apuesta política, resistencia, empoderamiento, acción colectiva.

\begin{abstract}
This article is the product of a research done by the research group GOGE (Management and Organizations from Emergent Perspectives), named "Organizational and Psychosocial Characterization of the Recycler Population from Chapinero Locality." The article contextualizes, from a critical perspective, the economic model embedded in Latin American organizational practices, which are reproduced in social processes and affect directly the community of recyclers. For this reason, an approach was made to the organizational practices of a group of recyclers, highlighting how people undertake empowerment processes as an alternative to politic action and in order to claim for fundamental rights, in the frame of a sustainability and self-management proposal.
\end{abstract}

\section{Keywords}

Organization, Political Commitment, Strength, Empowerment, Collective Action. 


\section{Contexto, tensiones y perspectivas}

En momentos en donde las tensiones politicas, sociales y económicas en el planeta se plantean como parte de la cotidianidad, y los discursos que median y operacionalizan prácticas, estructuras y formas institucionales, se movilizan de manera estratégica para consolidar finalmente relaciones de poder y de exclusión social, política y económica, se recrean dinámicas sociales, de carácter formal y no formal, que se repliegan y resisten a la apuesta particularmente reconocida como mercado, al cual durante décadas se han visto adheridos.

En este panorama donde se privilegia la producción, las lógicas de mercado y la excesiva individualización, reproducida en mandatos sectarios y explícitamente instrumentales cuyo principal interés es el de la comercialización de productos y servicios y la rentabilidad expresa en cada una de las acciones de intercambio y comercialización, termina segregando sectores concretos de la población en los cuales servicios básicos, educación formal y atención en salud resultan ajenos y en muchos casos inimaginados. Este contexto social, económico y politico permite explicar tanto las prácticas laborales como las relacionales de los recicladores, quienes en la actualidad hacen parte de toda una discusión respecto a su incorporación en el sistema privado de residuos sólidos, el cual parece ser lo suficientemente atractivo y necesario para el cuerpo de poder político institucional ${ }^{1}$. Con esto queda de manifiesto cómo sectores populares, tradicionalmente marginados, siguen expuestos a circunstancias de abandono y exclusión en los campos anteriormente mencionados, siendo su labor no solamente desprestigiada, sino inhabilitada y considerada por la nueva iniciativa, innecesaria. Por esta razón, y como respuesta a tan explícita situación social, aparecen escenarios nuevos de resistencia que para el caso concreto de los recicladores se manifiesta en nuevas experiencias que posibilitan dimensionar distintos tipos de prácticas y alternativas de integración y participación para la transformación y la dignificación, no sólo de su práctica del reciclaje, sino también como sujetos de derechos.

$1 \quad$ Las disposiciones legales que definen disposiciones reglamentarias para el uso y manejo de residuos sólidos se enmarcan en el decreto 1259 de diciembre de 2009.
Para la comprensión de este fenómeno local, vale la pena indicar cómo algunos aspectos de la geopolitica y la socioeconomía permiten situar mejor los fenómenos de exclusión y marginalidad. Por ejemplo, desde el siglo XVIII, en La riqueza de las naciones, Adam Smith, teniendo en cuenta las tendencias de la economia británica, los cambios generados en las relaciones económicas, las nuevas concepciones de la ciencia y la creatividad humana, planteó una era de prosperidad económica sin límites para las naciones. Pero, como no consideró la relación entre población y recursos, pronto surgieron nuevas concepciones sobre el progreso de la humanidad que pusieron en duda sus planteamientos. Estos planteamientos, junto con otros, han permitido abrir el debate sobre las nuevas economías y sobre las organizaciones que las integran, lo cual para el caso del presente artículo resulta pertinente y necesario.

En este sentido, la sociedad contemporánea se ha visto implicada en una serie de circunstancias sociales, económicas y politicas de mucha complejidad y diversidad, que se desprenden desde décadas de un modelo que paradójicamente se circunscribe en la lógica del bienestar y la dignificación, pero que finalmente moviliza sus esfuerzos hacia la explícita polarización de la misma. Es claro que el neoliberalismo termina fracturando la sociedad en cada una de sus dimensiones, especialmente en aquellas en donde se manifiesta la posibilidad de crecimiento equitativo y la satisfacción de necesidades sociales. América Latina es un claro ejemplo de cómo las lógicas del modelo han colapsado las posibilidades de ingresos fijos o empleos con garantías sociales formales, en detrimento de las calidades de vida de los pobladores pertenecientes a distintas generaciones.

Quizás pensar en el impacto del modelo es pensar en las formas como se comprenden los procesos sociales y los actores implicados; para el caso particular de América Latina resulta relevante reconocer cómo la implementación del modelo repercute francamente en inequidades y desmejoras directas de las condiciones de vida de los ciudadanos. Es por esto importante, y como parte de la reflexión que propone este artículo, que se reivindiquen y al mismo tiempo se promuevan las acciones colectivas, que se relacionan de manera especial con los menos favorecidos de la sociedad, entendiendo que con esto se resignifican las posiciones de decisión y acción de los ciudadanos (Fuentes, 2006, p. 27, citando a Rawls). 
Esta tensión evidente entre los postulados y exigencias propuestas por el modelo y la vida cotidiana, en donde se encuentra alojada la experiencia del trabajo y las construcciones comunitarias, define una serie de componentes que bien pueden explicar las prácticas y los nuevos sentidos del trabajo, del bienestar, de la familia y del Estado. Uno de los componentes que hacen parte de la discusión es el de desarrollo, entendido tradicionalmente como el proceso mediante el cual se propende por mejorar con el tiempo las condiciones de vida de una población o de sectores de la sociedad; sin embargo existe todo un marco teórico contemporáneo alrededor del mismo, que se aloja mejor con las ideas de resistencia y reivindicación de las comunidades más vulneradas. Este es el caso del concepto que insiste en el desarrollo como la eliminación de algunos tipos de falta de libertad que dejan a los individuos pocas opciones y escasas oportunidades para ejercer su agencia razonada (Sen, 2000, p. 19). Desde esta perspectiva, se entienden las faltas de libertad como pobreza, escasez de oportunidades económicas, privaciones sociales y abandono de servicios públicos. En este contexto, el enfoque de desarrollo resalta la idea de los sujetos como agentes activos de desarrollo, es decir que los considera propiciadores de cambios y corresponsables de sus procesos (Sen, 2000, p. 35).

De acuerdo con esto y entendiendo que el mejoramiento implica dignificación y recuperación de valores colectivos, un número significativo de ciudadanos y comunidades latinoamericanas, en respuesta a los planteamientos y a las prácticas sugeridas por el modelo, han generado diversas estrategias alternativas que hoy por hoy se constituyen como un serio referente en la construcción de nuevas y más dignas formas de comprender el desarrollo social y la calidad de vida de los pueblos (Barkin 1998). Dichas propuestas, que en muchos casos son llevadas a cabo con mucha propiedad y resultados interesantes, surgen en su mayoría por intereses de subsistencia y además por visibilizar el discurso y la práctica política que poseen las comunidades en su interior.

En este sentido es comprensible cómo el discurso del desarrollo termina dando respuesta a los diversos cambios y devenires de la sociedad que se instala en un modelo y demanda nuevas formas de inclusión en el territorio, como es el caso del modelo económico actual, internacionalizado desde décadas. Éste ha pretendido prometer mayores ganancias para el capital, siendo las manifestaciones contrarias a la riqueza las predominantes y las explicitadas a lo largo del continente. Es por esto que se expresa que el modelo globalizado de mercado y su interés por expandir su filosofia, ha polarizado las sociedades entre las más enriquecidas y las despojadas de derechos fundamentales, conocidas también como excluidas sociales, políticas y económicas (Barkin, 1992).

Vale aclarar que es esa naturalización ${ }^{2}$ del sistema global mundial, que privilegia sectores económicamente podérosos y fundamenta su accionar en la generación permanente de productos y servicios en el marco del mercado, en el establecimiento de aperturas comerciales y la propagación de la democracia liberal, lo que ha permitido, entre otras, la creación de nuevas maneras de respuesta de las comunidades, quienes han comprendido que la asociatividad, el empoderamiento, la solidaridad y la acción política, pueden convertirse en insumos para la construcción de una sociedad más justa y equitativa. En este sentido, se fortalece desde la base la capacidad económica y social y se complementa con el conocimiento y con las habilidades naturales de las poblaciones para proteger sistemas culturales, urbanos y naturales, de manera sustentable, a través de acciones políticas explícitas, entendiendo que la sustentabilidad además de insistir en conservar prácticas de preservación y cuidado, también dinamiza y reproduce discursos de inclusión y participación social.

\section{El empoderamiento como estrategia}

Para comprender cómo la comunidad responde a estas exigencias y define formas organizativas con otros valores y sentidos, se requiere hacer un abordaje acerca del trabajo, la interacción y la acción colectiva, la cual supone un conocimiento y una apropiación de la realidad, es decir que respectivamente se necesita tanto de la comprensión de la naturaleza como de los otros actores que circulan por el territorio. Vale aclarar que en este caso se considera ese conocimiento como inseparable de la acción y

2 La naturalización en este caso da cuenta del proceso de incorporación del modelo a las prácticas cotidianas. 
que está orientado básicamente por intereses construidos socialmente (Munné, 1982). ${ }^{3}$

Teniendo como base la población recicladora y su labor cotidiana, así como los proceso sociales que los involucra, resulta indispensable construir espacios que fortalezcan sus valores colectivos, para lo cual es necesario considerar procesos de empoderamiento como estrategia fundamentada en la transformación desde la convicción y desde la acción comunitaria. Es así como aparecen conceptos que se relacionan con el empoderamiento, como el de compromiso colectivo, "engagement", el cual expresa una intención pública para la realización de acciones de carácter colectivo (Klinger, 2000). En este sentido, en el contexto de la reflexión de población recicladora, es posible definir el empoderamiento como el proceso selectivo, consciente e intencionado que tiene como objetivo igualar oportunidades entre los actores sociales. Es selectivo ya que el criterio central es el de identificar y contribuir con la transformación de sectores sociales excluidos. Su transformación hace más equilibradas las relaciones de poder y quienes han sido excluidos tienen posibilidades de ser actores de su propio desarrollo.

Etimológicamente, el concepto de empoderamiento alude a permitir, capacitar, autorizar, o dar poder sobre algo o alguien, o para hacer algo. Antes, el Diccionario de Oxford lo consideraba como delegación de poder; ahora su definición considera empoderar como "to enable", es decir permitir a uno hacer algo de manera concreta respecto a una necesidad concreta. Conceptualmente, se refiere al proceso o mecanismo a través del cual personas, organizaciones o comunidades adquieren control o dominio sobre asuntos o temas de interés que le son propios. Desde esta perspectiva es muy claro cómo se reinventa el modelo tradicional intervencionista que define la postura de un experto el cual responde en solitario a la naturaleza del problema, definiendo también las estrategias metodológicas y de evaluación, relegando a los miembros de la comunidad a simples ejecutores de acciones determinadas. Con esta denominación que históricamente se ha instalado en las ciencias sociales, los individuos y las colectividades carecen de competencias para hacerse cargo de su

$3 \quad$ Frederic Munné, en su trabajo sobre Psicologías sociales marginadas, establece cómo la perspectiva contemporánea para el abordaje de lo social, incluye referentes de acción política. realidad y se refuerza la falta de poder que se tiene frente a las propias condiciones y circunstancias de vida (Le Bossé, 2002).

De acuerdo a esto, son muchos los autores e investigadores sociales que le apuestan al desarrollo del empoderamiento de las personas y las comunidades. La tesis del empoderamiento promueve la consideración de las personas como ciudadanos con derechos y opciones para el desarrollo; así mismo promueve una nueva aproximación a la relación con los profesionales que intervienen, denominándolos como agentes colaboradores que trabajan con y desde la comunidad (Rappaport, 1981).

Rappaport (1987) definió empoderamiento como un proceso o un mecanismo mediante el cual las personas, organizaciones y comunidades logran control sobre sus asuntos. Además señala que para el caso del empoderamiento comunitario se pueden identificar dos componentes complementarios: el primero se centra en la autodeterminación personal, entendida como la capacidad de determinar la propia vida (sentido de competencia personal), y el segundo se centra en la determinación social que se refiere a la posibilidad de participación democrática (sentido de competencia comunitaria). Existen sin embargo otras posiciones que incluso critican esta definición, considerando que el concepto puede conducir al error de creer que los agentes externos que tienen poder, pueden transferirlo automáticamente a quienes carecen de él. Sin embargo, si se considera el sentido original del concepto de empoderamiento en la comprensión otorgada por Dufort (2002), queda claro que el poder no se transfiere sino que se desarrolla en un proceso complejo. Desde una posición generativa del poder, éste se construye, y la labor del agente de desarrollo es acompañar en ese proceso al colectivo (Taliferro, 1991).

Para Zimmerman (2000), existen componentes como la acción colectiva, la conciencia critica y la movilización de recursos que también se consideran propias del proceso de empoderamiento, en el que son básicos tanto la participación con otros para lograr metas, como los esfuerzos para generar acceso a los recursos y una comprensión crítica del medio sociopolítico. En el nivel organizacional, el empoderamiento incluye procesos y estructuras que animan la participación y estimulan la efectividad organizacional, así como también se considera como proceso que se refiere a acciones colectivas dirigidas a mejorar las condiciones de 
vida y el reconocimiento entre las mismas organizaciones. Esta apuesta por el empoderamiento supone, además, nuevas formas de comprender el desarrollo local, entendiéndose como un desarrollo endógeno. Es decir multicausal, sistémico y complejo que surge desde la base, bajo la dirección y orientación de la comunidad (Bustamante, 2003), considerándose como categorias interdependientes el territorio, las subjetividades, el capital social y los recursos.

Otro de los aspectos que se desprenden de esta iniciativa, es el de la organización comunitaria como eje transversal para toda acción colectiva, en donde la estructura social que la integra y le da sentido, sugiere de los miembros alta cohesión e integración (Carballeda, 2010). Para poder comprender la estructura y funcionamiento de estas organizaciones es indispensable comprender las relaciones que en ellas se generan, incluyendo su historia, sus dinámicas relacionales y sus formas de liderazgo; todas estas entendidas como procesos y no como elementos estáticos (Shein, 1998).

Es claro que junto a conceptos como el de empoderamiento y organización comunitaria ${ }^{4}$, se encuentran algunos que finalmente aparecen como convergentes y trascendentales para la discusión, como es el caso del capital social, el cual le provee a la nueva concepción de desarrollo otros componentes que promueven lo humano y sus potencialidades. Bajo esta línea, el capital social inscrito en la nueva perspectiva de desarrollo, en la que no se privilegia el consumo sino las relaciones sociales, las apuestas culturales y la acción colectiva, permite a las organizaciones alternativas comprenderse y dinamizar sus acciones de forma distinta. Se puede apreciar cómo existe entonces una estrecha relación entre los conceptos de empoderamiento en el nivel comunitario organizativo. Ambos aluden a la relevancia de los recursos y las competencias humanas en la forma de redes asociativas que pueden brindar apoyo o colaboración en los propósitos de la comunidad.

Desde este enfoque de redes estructurales presentes en las teorías del capital social por

$4 \quad$ Los conceptos de empoderamiento y organización comunitaria hacen parte de la construcción establecida para los abordajes internos desde la psicología comunitaria, en los cuales aparece el componente político como dimensión de reivindicación para la transformación. ejemplo, se considera que los vinculos existentes, concebidos como redes sociales en tanto fuentes de capital social, son uno de los factores endógenos asociados a las experiencias de empoderamiento comunitario (García, 2005). En este orden de ideas, es indispensable además reconocerle a la lógica del empoderamiento y la organización comunitaria su componente politico natural que hace parte de los procesos de fortalecimiento y transformación social (Roberts, 2001). Entonces, la naturaleza de las relaciones establecidas entre los diversos actores involucrados en una comunidad, podría potenciar los recursos de ésta, favoreciendo el ejercicio de una ciudadanía activa, o por el contrario, fomentar relaciones que continúan marginando o reproduciendo las prácticas cotidianas sugeridas por la institucionalidad y la estructura sugerida por el modelo, que terminan casi siempre en exclusión social y desigualdad.

\section{La perspectiva de la sustentabilidad del desarrollo}

Para hacer esta distinción, resulta indispensable recurrir a la categoria globalización la cual propone de manera recurrente y abiertamente mercantil, cambio constante de escenarios y prácticas para los sujetos y las organizaciones sociales, enmarcado por elementos contradictorios y plagados de incertidumbres, donde la lógica económica termina orientando el funcionamiento de las organizaciones hacia la obtención de un máximo rendimiento, considerándose este elemento el detractor principal del desarrollo de las comunidades y del contexto sociocultural que las circundan (Constanza, 1999).

Dentro del ejercicio por comprender las dinámicas organizacionales de los recicladores en Bogotá y sus lógicas por hacer más visibles sus apuestas politicamente colectivas, y teniendo en cuenta que sus prácticas laborales desafian las estructuras impuestas por el mercado, es indispensable hacer la revisión respecto a la perspectiva de sustentabilidad que acompaña dichas prácticas, ya que puede decirse que el interés por la sustentabilidad también se ha globalizado. Cada vez son más las comunidades que le temen al deterioro de la calidad de vida, y que así mismo son conscientes de que los patrones de consumo dimensionados desde el modelo, considerados como injustos y además antidemocráticos, amenazan la continuidad de las organizaciones 
sociales. Es claro que la sustentabilidad no es solamente un asunto del ambiente de justicia social y de desarrollo, también es un asunto de la cotidianidad de la gente y de cómo sobreviven los individuos, las colectividades y las culturas.

Dentro de esta perspectiva aparecen diversas estrategias; una de ellas establece que la sustentabilidad debe focalizarse en la importancia de la participación local y en la revisión acerca de cómo la gente vive y trabaja, así como en la autonomía local y regional como componente indispensable en la discusión sobre la integración. Vale aclarar que dicha autonomía que sugiere la sustentabilidad, nada tiene que ver con la ausencia de cooperación entre comunidades y regiones. La respuesta en este caso debe ser reflexiva y debe confrontar las realidades de una sociedad global urbanizada en crisis que dificilmente ha logrado resolver las necesidades más elementales a sus ciudadanos (Barkin, 1992). La lógica del desarrollo sustentable hace referencia entonces, a cómo la reorganización productiva que resuelven tener comunidades posee un común denominador que es la participación democrática para la instrumentalización de proyectos de desarrollo local. En este sentido, la sustentabilidad es entendida como el proceso por medio del cual una comunidad organizada produce y se permite pensar en producir en el futuro, siempre cumpliendo con la responsabilidad que supone la defensa de la justicia social y la solidaridad entre generaciones (Ling, 1998). Así se constituye como sustentable la forma más contemporánea y crítica de desafiar la corriente sostenible que prácticamente insiste en preservar las lógicas neoliberales de rentabilidad y consumo en contextos de vulnerabilidad.

Comprender entonces esta noción que sugiere situar las organizaciones sociales en un contexto altamente cambiante y lleno de complejidades, implica apropiar nuevas formas de significación respecto a la relación de las mismas con el entorno, es decir contemplar los niveles de afectación que como sistema abierto tienen las organizaciones sociales con su escenario de desarrollo, que para el caso de los recicladores sería la ciudad (Zanderbergen, 1995). Así mismo, la sustentabilidad resignifica al sujeto ${ }^{5}$, considerándolo como el centro

5 Las consideraciones del sujeto de la posmodernidad, permiten circunscribirlo en la dimensión de la reflexión y la acción como parte de la transformación del entorno. Esta perspectiva lo sitúa finalmente como sujeto testigo y comprometido con el desafío del cambio. y la razón de ser del proceso mismo de desarrollo, es decir posicionándolo como sujeto politicamente responsable frente a las disposiciones y determinaciones de carácter público, dándole con esto a la perspectiva de desarrollo emergente una denominación más incluyente y deliberadora, incluso para la formulación de politica pública.

Si bien la tendencia globalizadora tiene como objeto permear todas y cada una de las prácticas y caracterizaciones organizacionales, existe también la contratendencia que propende por no sólo desafiar las consideraciones hegemónicas del mercado, sino, desde un carácter propositivo, plantear formas alternativas de producción e incluso de consumo que repercutan en la reconfiguración del territorio, de los sujetos y de sus relaciones sociales, politicas y culturales. Como respuesta a la línea marcada por el régimen globalizador, aparece la dimensión de resistencia que, junto con el capital social, reorientan las lógicas de las organizaciones sociales, las instituciones e incluso de los mismos ciudadanos, fortaleciendo la noción de bien público basado en aspectos como la confianza, las redes de acción colectiva, la reciprocidad, la corresponsabilidad y el compromiso (Putnam, 1993). Tales relaciones se forman de diversas maneras como las enseñanzas mutuas y colaborativas, las conexiones personales y familiares, las membrecias que se interlapan y se deconstruyen, la movilidad interorganizacional, y los proyectos de desarrollo social.

Para el caso de las organizaciones de recicladores, como para diferentes organizaciones sociales, esta perspectiva transita, se reconoce y se afianza como transversal en su actuar politico local y se constituye como reto colectivo para mejorar las condiciones de las organizaciones mismas, de los trabajadores y de su condición de ciudadanía.

\section{La apuesta política}

El caso de las organizaciones de recicladores de Bogotá bien puede circunscribirse en el escenario de lo políticamente manifiesto, es decir visible y con pretensiones de restablecer su incorporación en los procesos de manejo de residuos que tanto impacto $\mathrm{y}$ repercusión social y politica vienen teniendo y tendrán con las comunidades relacionadas directa o indirectamente con estas prácticas. Es decir que, en este caso particular, las consideraciones 
politicas que circulan a las prácticas organizacionales de los recicladores en Bogotá, deben incluir reflexiones directas sobre la participación ciudadana en la defensa y promoción de derechos fundamentales que se relacionan con cambios estructurales, con la vida económica y sobre todo con la expresión de nuevas formas de convivencia, de trabajo, de asociatividad y de acción colectiva.

Habría necesidad entonces, de comprender cómo estas organizaciones representan no solamente dinámicas sociales, sino que además representan intencionalidades civiles por recuperar espacios legitimos de participación política. Es claro que para este propósito debe aclararse la denominación que en el contexto latinoamericano se ha construido por sociedad civil, la cual parece ser la figura en el centro del debate contemporáneo sobre la democracia y el desarrollo en el continente; el término sociedad civil incluye además temas que van desde la vida cotidiana, las relaciones interpersonales y las organizaciones sociales de base. Así mismo y desde la condición contemporánea del concepto, se puede afirmar que esta no se encuentra ajena ni al Estado ni al mercado mismo, siendo el concepto de ciudadanía reconocido y apropiado por nuevos sectores de la sociedad, donde se resignifica el sujeto como actor social reflexivo y transformador en el contexto. De acuerdo a esto, se establece que para que exista una sociedad civil con garantías sociales y políticas reconocidas, ésta debe contemplarse dentro del marco de la participación que existe en el contexto de la vida social. Para que esta participación se dirija a destinos propositivos y transformadores, los individuos deben reconocerse como organizados en función del restablecimiento de derechos y del reconocimiento de deberes, es decir, establecer diversas formas y tipos de relaciones sociales; de lo contrario al no existir cohesión en el entramado social, se terminará legitimando la exclusión y las desigualdades sociales (Vargas, 2007).

No obstante, aunque las distintas tesis de participación social reportan movilidad y apuesta colectiva, resulta indispensable aclarar cómo la propuesta crítica emergente reconoce y reivindica el sentido de lo público en el que se encuentran enmarcadas las acciones colectivas. Permite además situar al sujeto en relación con las apuestas transformadoras en el contexto, es decir reproducir acciones en el marco de la corresponsabilidad e incluso la autogestión, ya que al mismo tiempo que se mejoren sus capacidades, adquieran nuevas habilidades y destrezas, aumentan su autoconfianza e incrementan la interacción social gracias a la construcción de formas de organización, lo cual en últimas implica la construcción de nuevas formas de relación social (Nabossa, 2006).

Es entonces en este contexto que la participación se establece como epicentro o eje transversal para el desarrollo donde los sectores populares como sujetos de esa participación se encuentran en capacidad para establecer un control sobre los procesos de concepción, planificación, ejecución, evaluación y sistematización de su propio desarrollo. Tal y como lo propone Meza (1995) "la participación popular se alcanza cuando las organizaciones de base tienen una estrategia propia en materia de producción y defensa de los derechos humanos" (p. 38).

\section{El caso de de ASOCHAPINERO, Una propuesta de reivindicación política ${ }^{6}$}

El proceso de investigación en este caso permitió comprender las percepciones y apuestas que, como experiencia colectiva, se han construido en medio de las tensiones politicas y sociales presentadas en la actualidad hacia la población recicladora de la ciudad. Para tal efecto se contó con el grupo de recicladores que hacen parte de ASOCHAPINERO, asociación que reúne población recicladora organizada con el fin de mejorar condiciones de vida laboral y promover acciones colectivas en función de visibilizar y reivindicar la práctica del reciclaje en una ciudad altamente excluyente social, politica y laboralmente.

\section{Metodología, resultados y análisis de la información}

La metodología propuesta para el proceso se enmarcó en la perspectiva cualitativa, con tipologia discursiva interpretativa, rescatando las versiones y construcciones conversacionales de la población vinculada con el mismo. Desde esta perspectiva se incluyeron encuentros narrativos y entrevistas de profundidad

6 La Asociación de Recicladores de Chapinero, organización adscrita a la ARB (Asociación de recicladores de Bogotá), se constituye como un referente local de organización de base que propende por la reivindicación de la labor. 
que permitieron hacer explícitas las percepciones respecto a las categorias de análisis: sustentabilidad, empoderamiento y acción politica.

Dadas las características de la población, su nivel de cohesión y su experiencia respecto a asuntos particulares de la labor de reciclaje, se pudo recoger suficiente información para comprender asuntos organizativos referidos a la comprensión del concepto, a las motivaciones e intereses que rodean la constitución organizativa, la priorización respecto a acciones y estrategias, así como la apropiación de la perspectiva politica asociada a su labor; todo esto desde el marco dispuesto por las categorias de análisis anteriormente mencionadas.

\subsection{Sustentabilidad, trabajo colectivo y apuestas para el desarrollo}

Desde la perspectiva del desarrollo sustentable, que privilegia categorias reivindicadoras de lo humano y de preservación de derechos fundamentales, cabe la reflexión acerca de cómo se concibe la práctica recicladora en un ambiente plagado de mandatos liberales de consumo y de apuestas por la individualización y la supervivencia. Es decir que resulta pertinente hacer explícitas las consideraciones que los asociados a ASOCHAPINERO han construido no sólo acerca del desarrollo social, sino además del compromiso por el mejoramiento y la preservación de condiciones de dignificación de la labor, de la vida, de las relaciones y del entorno.

La organización respecto a este aparte considera en primera instancia su labor como indispensable para la ciudad, debido a que el tema de la basura y los residuos sólidos que circulan diariamente, requieren de un cuerpo de trabajadores que resulten finalmente comprometidos con su cuidado. A este respecto aparecen versiones como:

Sin nosotros la ciudad seria un caos. Por más que se piense en sacarnos del negocio, somos necesarios para muchos, imagínense el daño que tendría para la ciudad la basura arrumada en las calles, o por ejemplo lo que seria para la ciudad que la basura no llegara al relleno. Los daños no son solamente sociales sino también ambientales y de salud.
Por otro lado, la práctica es considerada como indispensable para el desarrollo y para la consolidación de nuevas relaciones sociales, así como para promover mejoramiento del entorno inmediato. Cabe anotar que la perspectiva de la sustentabilidad del desarrollo sugiere que la comunidad organizada produce y se permite pensar en producir en el futuro, siempre cumpliendo con la responsabilidad que supone la defensa de la justicia social y la solidaridad entre generaciones, es decir considerar al sujeto como politicamente responsable frente al cambio social. A este respecto, la experiencia organizativa de la Asociación de Chapinero, ha reportado situaciones y acciones que bien pueden relacionarse con el sentido de sustentabilidad, ya que a partir de consensos básicos, en los cuales participan los asociados de forma permanente, se han permitido construir escenarios presentes de acuerdos para el mejoramiento y se discuten además escenarios futuros de trabajo. Si bien esta lógica de sustentabilidad expresa la importancia de mantener grados explícitos de empoderamiento y organización comunitaria, asunto en los que la asociación viene comenzando un proceso de apropiación de lo colectivo, se podrian establecer algunos componentes de asociatividad adscrita a la misma como se expresa en el siguiente fragmento:

Con la organización hemos crecido, nos hemos comprometido, las cosas no son iguales a como eran antes de asociarnos, no es lo mismo estar solos consiguiendo las fuentes. Ahora y con ayuda de ENDA, nos podemos entender como grupo e incluso como familia en algunos casos. El futuro depende de cómo trabajamos en el presente.

Con este fragmento queda manifiesta la relación presente-futuro en la que insiste la sustentabilidad, poniéndose de manifiesto la pretensión colectiva por pensar el futuro en condiciones diferenciadoras y con mejoramiento explícito dentro del escenario comunitario.

\subsection{El legítimo poder de las comunidades}

Dentro del marco de la segunda categoría, denominada para el estudio empoderamiento, se pudieron recoger, luego del desarrollo metodológico, versiones y percepciones relacionadas con su constitución organizativa y la forma como se ha construido y emprendido 
una estrategia de visibilización y reivindicación tanto de su labor como de sus prácticas cotidianas. Es necesario entonces insistir en que las organizaciones, desde su constitución, comienzan a construir procesos de diversa indole; algunos de estos podrian considerarse como procesos donde el legítimo poder de la organización se hace presente como base y soporte para la acción y desarrollo de tareas, búsquedas, propuestas y estrategias que finalmente comprenden una idea de gestión de base, tan importante en la lógica del nuevo desarrollo, en la medida en que los sujetos tradicionalmente excluidos adoptan formas estructurales y dinámicas que les acredita como responsables de su propio cambio y transformación. Esta idea de empoderamiento colectivo puede hacerse explícita en los siguientes fragmentos:

\section{Hay momentos en donde nos podemos sentir fuertes, como en las marchas, también cuando logramos tumbar un decreto. Antes todo el mundo nos miraba con desconfianza y hasta violencia, hoy las cosas son un poco diferentes.}

No todos tenemos el mismo compromiso, además porque no todos vemos las cosas igual, pero si se ha mejorado mucho con la organización, con las reuniones y con otras cosas que hacemos por nosotros los recicladores y por nuestras familias.

Se puede identificar con estos fragmentos cómo, por un lado, la organización ha permitido otros niveles de reconocimiento hacia afuera, es decir que se resignifica para distintos sectores de la población la labor de reciclador y las prácticas asociadas también a la defensa y la reivindicación de sus derechos y de sus formas de vida. Cabe expresar cómo para el caso del empoderamiento se disponen dos dimensiones como son la competencia personal, que en este caso supone la incorporación de nociones de bienestar y reconocimiento, y la competencia comunitaria que expresa la apropiación de sentimientos de reconocimiento colectivo, particularmente frente a las acciones que redundan en el bien común.

Otro aspecto que también puede hacer parte del análisis del empoderamiento se relaciona directamente con los compromisos adquiridos por el grupo de asociados y la manera como

estos repercuten en los logros y en posicionamiento de la organización ante otras organizaciones e instituciones incluso de carácter estatal. En este orden de ideas se considera el compromiso colectivo como una evidencia clara por visibilizar una intención construida que redunde tanto en el diálogo constante con el entorno, como en la convicción para su transformación. Estos principios se alojan y se terminan exponiendo en fragmentos como:

\begin{abstract}
El compromiso es indispensable para lograr cosas con la organización, el tema no es de poner solamente la cuota sino creer en lo que se hace, que igual es de beneficio de todos. Por eso la gente y las mismas organizaciones incluso internacionales saben quiénes somos y por qué nos la estamos peleando.
\end{abstract}

\section{Somos reconocidos y hasta un premio nos dieron en el encuentro mundial de recicladores. Debe ser que algo de lo que hacemos es importante, aunque todavia existan algunos que no creen.}

Con lo anterior, queda de manifiesto en un principio la comprensión acerca de cómo la organización ha requerido en los asociados no sólo movimientos y acciones hacia afuera, sino además supone una permanente elaboración de misiones y sentidos al interior de la misma. Estas construcciones permean lo relacional y posibilitan la construcción de sentimientos colectivos que acompañan la gestión misma, la cual resulta visible y reconocida; sin embargo se rescata cómo estas construcciones resultan más fácilmente apropiadas por unos, siendo para algunos de los asociados circunstancias que incluso no terminan de sentir como propias de un trabajo colectivo.

\subsection{La acción colectiva como estrategia de resistencia política}

Si bien el concepto de resistencia no hace parte del cuerpo categorial del estudio, para el caso de la acción colectiva éste se convierte en elemento constitutivo y transversal para la comprensión de lo político en el escenario de las organizaciones de recicladores. El asunto de lo político en la Asociación de recicladores de Chapinero tiene como fundamento la 
apuesta por la defensa de la práctica laboral del reciclador y sus posibilidades de participación en la agenda pública que los compromete y los impacta de manera directa e indirecta. La acción política como tercera categoría del estudio reporta varios componentes entre los que aparecen la política pública, el discurso alternativo de resistencia y el desarrollo de estrategias para la transformación, los cuales se expresan de forma particular en los siguientes fragmentos expuestos por los asociados:

Con la organización nos acercamos también a la ley, asi no sepamos todos leer, siempre sabemos qué está saliendo y asi organizarnos mejor. Con ENDA se aprende y se capacita uno en la ley. Todo esto nos sirve para tener un mejor conocimiento $y$ no dejarnos, hasta hemos tumbado unos decretos, por todo eso ya nos invitan a reuniones de lo del relleno $y$ otros proyectos.

Establecer una relación con la política pública, en este caso, supone pensar en un actor reflexivo y activo que no solamente reporta un conocimiento, sino que establece un actuar concreto respecto al mismo, es decir que para el caso de la organización es indispensable tener la información y conocerla, pero además plantear acciones respecto a la misma, de manera tal que las afectaciones sentidas por lo normativo, representen acciones colectivas que hacen explícita la dimensión politica que la define. Lo público no resulta siendo algo ajeno, sino algo que constituye incluso la razón de ser de la organización, incluso más allá de lo que significa la labor de reciclaje.

Además de esto, también dentro de la acción colectiva, es posible dar cuenta de una construcción discursiva que se aparta de la lógica estructural de mercado en la que se instala una línea de producción y trabajo. Esta perspectiva posibilita operar desde una dimensión alternativa, la cual no pretende alinear las prácticas a ordenes jerarquizados, sino que por el contrario alimenta la consolidación de un escenario marcado por relaciones cercanas, solidarias y colaborativas, que propenden por la prospectiva en términos de cambio y transformación para el beneficio común, como lo pueden establecer los siguientes fragmentos:

La Asociación busca mejorar las condiciones de trabajo de todos, para esto hay que colaborarnos y tener en cuenta que juntos podremos hacerlo, no es fácil para uno solo; afuera es dificil conseguir un trabajo, entonces hay que organizarnos para buscar fuentes. Hay que mejorar las relaciones y otras cosas que nos faltan para seguir en la lucha.

Todos nos unimos a la hora de una marcha y nos comprometemos con nuestra acción, muchas organizaciones también participan pero nosotros casi siempre somos los más comprometidos y los más unidos, todavía nos hace falta mucho, pero hay que actuar antes de que lo hagan otros.

Queda entonces de manifiesto la idea de que la Asociación tiene, desde sus miembros, un compromiso por emprender acciones colectivas e incluso de hecho, para hacer valer derechos fundamentales que históricamente han sido vulnerados por la institucionalidad y por sectores diversos de la población. Es clara la postura que refleja la misión frente al restablecimiento de sus derechos civiles y laborales, para lo cual se vienen tejiendo relaciones de confianza y de compromiso mutuo, no solamente para intervenir en procesos políticos, sino además para resignificarse como agentes activos y propositivos en la ciudad.

\section{Conclusiones}

La experiencia de investigación con los asociados a ASOCHAPINERO, organización de recicladores adscritos a la Asociación de recicladores de Bogotá, ha significado en principio todo un proceso de construcción de confianza, reconocimientos y desafíos, quizás porque organizaciones sociales y populares, la academia, ONGS e Instituciones del Estado, de manera irresponsable, han intervenido de forma excluyente, utilizando la población para fines distintos a los de promover y reivindicar. En este sentido, el proceso que exigió cercanias y acompañamientos constantes, permitió dar cuenta de todos los elementos constitutivos del proyecto, de forma clara, precisa y en algunos casos, contundente, de forma natural, utilizando estrategias metodológicas que además de acordarse con el grupo, se desarrollaron de manera participativa y espontánea. 
El proceso permitió comprender cómo la actividad del reciclaje posee ya en la ciudad un carácter colectivo y comunitario, donde la actividad deja de asociarse con una práctica convencional e incluso hasta innecesaria, para convertirse en algunos casos ejemplo de trabajo asociado con intencionalidad politica reivindicadora; esto ha permitido que las organizaciones no solamente aparezcan y se desarrollen, sino que además se constituyan incluso en un referente para la denominación y la comprensión de la labor en la ciudad.

El clima liberal y mercantil que ha permeado la sociedad latinoamericana, las organizaciones y las dinámicas sociales, en las que se encuentran inmersos los recicladores, sirve de referente a la hora de explicar las formas alternativas que desarrollan las organizaciones populares que históricamente se han visto excluidas por los principios y exigencias de la institucionalidad. En este sentido, la organización ASOCHAPINERO no se puede separar de esta explícita circunstancia del contexto y se piensa en términos de mejorar, a partir de la construcción de un marco colectivo, condiciones de vida social, familiar y laboral.

Si bien el proceso de desarrollo incorpora categorias relacionadas con el impacto económico y social, vale la pena resaltar cómo la perspectiva contemporánea de desarrollo desafía la corriente del ingreso, la rentabilidad y el consumo, y propone comprenderlo de forma integral, es decir comprender que las prácticas, en este caso laborales, incluyen componentes sociales, socioafectivos, axiológicos y culturales, los cuales de manera interdependiente recrean nuevos escenarios para las relaciones sociales e incluso para las mismas relaciones interinstitucionales.

Con esto, la idea de sustentabilidad del desarrollo permite, no solamente pensar en una producción para la supervivencia, sino que particularmente se circunscribe en un escenario prospectivo de cambio y mejoramiento, donde se produzca para sí como comunidad, preservando niveles de autonomía, autodeterminación y relaciones colaborativas y solidarias. Para el caso de la organización de recicladores, aunque si bien se perciben construcciones colectivas para el sostenimiento, no se hacen todavia muy explícitos otros componentes de la sustentabilidad como la autogestión y la corresponsabilidad, siendo todavía en la labor y en algunos otros asuntos de la organización, la individualidad y la supervivencia los elementos que permanecen más evidentes.
Por otro lado, resulta interesante cómo la organización de recicladores ha emprendido, de manera natural y espontánea, un camino hacia la consolidación y hacia la visibilidad; en este proceso la relación con la organización no gubernamental ENDA, ha resultado indispensable tanto para el acompañamiento como para la formación de los asociados, quienes sienten apropiación y pertenencia con los asuntos a los que se les convoca. Podría considerarse que la organización, a este respecto, adelanta un proceso de fortalecimiento de procesos, los cuales han estado mediados por un interés común de reivindicar la labor de reciclaje en la ciudad de Bogotá, lográndose con esto reconocimiento y referenciación por parte de otras organizaciones y entidades estatales.

Otro aspecto para rescatar es el de la dimensión política asociada a las prácticas inmersas en la organización, ya que ésta sin lugar a dudas se considera como el epicentro de desarrllo de toda organización popular que propende por legitimar su labor y por reivindicar valores $\mathrm{y}$ derechos fundamentales vulnerados por el Estado. En el caso de los recicladores, esta dimensión se ha convertido en el desafio que transita por cada una de las acciones que desarrollan, asunto que se ve reflejado tanto en la forma como se vienen incorporando a las demandas adscritas a lo normativo, como en las decisiones colectivas por controvertir de forma critica y bien argumentada cada una de las que los compromete como trabajadores y ciudadanos, manifestándose expresamente el espíritu colectivo que circula por la organización.

Si bien se pueden considerar como explícitos elementos propios de la acción colectiva, el empoderamiento y la resistencia en la organización de recicladores, estos terminan siendo parte de un proceso todavía prematuro pero en emergencia, es decir que se comienzan a desarrollar como parte del proceso natural de la misma, aunque no se tengan en muchos casos las claridades acerca de su concepción y sus implicaciones dentro de las dinámicas del colectivo.

Para finalizar, cabe resaltar cómo a pesar de que la organización viene sorteando diversas situaciones que incluso ponen en peligro su desarrollo y supervivencia, como lo son los intereses privatizadores de la política ambiental frente al manejo de residuos y el constante rechazo de distintos sectores de la sociedad, ésta decididamente define formas 
alternativas de supervivencia que bien podian constituirse como de resistencia misma al modelo económico del trabajo, circunstancia que los ubica en un panorama que bien podría definirse como crítico pero a la vez también propositivo y reivindicador. 


\section{Referencias}

1. Bustamante, G. (2003). Iniciativa del etnodesarrollo endógeno local. Temuco: Universidad de la frontera.

2. Barkin, D. (1998). Riqueza, pobreza y desarrollo sustentable. México: Editorial Jus.

3. Carballeda, A. (2002). La intervención en lo social: La exclusión e integración en los nuevos escenarios sociales. Santiago del Estero: Paidós.

4. García, M. (2005). El surgimiento de la cooperación entre actores que operan instrumentos de la política pública.

Temuco: Universidad de la frontera.

5. Klinger, E. (2000). Commitment. APA, Oxford University, London.

6. Le Bosé, Y. (2002). El empoderamiento de las personas y comunidades: otras formas de intervenir. En Dufort (Ed.), Agir au coeur des communautés (pp. 75-115).

7. Meza, Q. (1995). Jóvenes y niños trabajadores: sujetos sociales, protagonismo, estrategias y metodologías. IFEJANT: Lima.

8. Munné, F. (1982). Psicologías sociales marginadas, la línea de Marx en la psicología social. Barcelona: Hispano Europea, S.A.

9. Nabossa, A. (2006). "Participation as a means to enhance human security with special reference to gender". IV Encuentro Mundial de intelectuales y artistas en defensa de la humanidad. Roma.

10. Rappaport, J. (1987). Terms of empowerment. American journal of community Psychology, número 15, 121-148.

11. Roberts, B. R. (2001). "Las nuevas políticas sociales en América Latina y el desarrollo de ciudadanía, una perspectiva de la Interfaz." Ponencia presentada en el taller Agencia, Conocimiento y Poder. Nuevas direcciones, Wageningen. Holanda.

12. Shein, E. (1998). Consultoría de procesos. Volúmen 2. Addison - Wesley beroamericana. México.

13. Taliferro, M. B. (1991). The myth of empowerment. The journal of negro education 60/I: 1-2.

14. Vargas, I. (2007). Resistencia y participación. Caracas: Monte Avila editores.

15. Vilas, C. (1994). La hora de la sociedad civil. Bogotá: IEPRI. UN.

16. Zimmerman, M. (2000). Empowerment Theory: Psychological, Organizational and Community Levels of Analysisis. Nueva York: Plenum Publishers. 


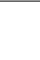

